\title{
Human GPR4 and the Notch signaling pathway in endothelial cell tube formation
}

\author{
JUAN REN ${ }^{1}$, YUELANG ZHANG ${ }^{2}$, HUI CAI $^{3}$, HONGBING MA $^{4}$, DONGLI ZHAO ${ }^{1}$, XIAOZHI ZHANG ${ }^{1}$, \\ ZONGFANG LI ${ }^{4}$, SHUFENG WANG ${ }^{1}$, JIANGSHENG WANG ${ }^{1}$, RUI LIU ${ }^{1}$, YI LI ${ }^{1}$, JIANSHENG QIAN ${ }^{1}$, \\ HONGXIA WEI $^{1}$, LIYING NIU ${ }^{1}$, YAN LIU ${ }^{1}$, LISHA XIAO ${ }^{3}$, MUYANG DING ${ }^{3}$ and SHIWEN JIANG ${ }^{5}$ \\ ${ }^{1}$ Department of Radiotherapy; ${ }^{2}$ Imaging Department, First Affiliated Hospital of Xi'an Jiaotong University; ${ }^{3}$ Medical School, \\ Xi'an Jiaotong University; ${ }^{4}$ Department of Oncology, Second Affiliated Hospital of Xi'an Jiaotong University, \\ Xi'an, Shaanxi 710004, P.R. China; ${ }^{5}$ Department of Biomedical Science, \\ Mercer University School of Medicine, Macon, GA 31207, USA
}

Received April 19, 2015; Accepted February 29, 2016

DOI: $10.3892 / \mathrm{mmr} .2016 .5380$

\begin{abstract}
G protein-coupled receptor 4(GPR4) is hypothesized to function as a $\mathrm{pH}$ sensor and is important in the regulation of proliferation, migration and angiogenesis of vascular endothelial cells (ECs). Furthermore, the Notch signaling pathway is significant in the regulation of the angiogenic behavior of ECs. However, whether GPR4 regulates angiogenesis via the Notch signaling pathway remains unclear. The present study evaluated the effect of Notch signaling in human GPR4-induced angiogenesis in HMEC-1 cells. The results revealed that GPR4 increased Notch1 expression in a time-dependent manner. In addition, the inhibition of Notch1 expression using small interfering RNA or the Notch receptor inhibitor, $\gamma$-secretase inhibitor I, significantly blocked GPR4-induced HMEC-1 tube formation and lymphocyte transendothelial migration. Furthermore, the inhibition of Notch1 blocked GPR4-induced vascular endothelial growth factor and hypoxia-inducible factor $1 \alpha$ expression. Thus, it was demonstrated that GPR4 affects ECs by regulating Notch1, a function that may be important for physiological and pathological angiogenesis.
\end{abstract}

\section{Introduction}

Although the signal transduction cascade of the Notch signaling pathway is simple, it is able to precisely control multiple binary cell fate decisions, cell proliferation and differentiation, and stem cell maintenance during embryogenesis and postnatal development $(1,2)$. The dual activity of its nuclear effector, recombination signal binding protein for immunoglobulin $\kappa$ $\mathrm{J}$ region $\left(\mathrm{RBP}-\mathrm{J}_{\kappa}\right)$ is crucial to the dynamics of Notch signaling

Correspondence to: Dr Juan Ren, Department of Radiotherapy, First Affiliated Hospital of Xi'an Jiaotong University, 277 Yan Ta Xi Lu, Xi'an, Shaanxi 710004, P.R. China

E-mail: juanren88@126.com

Key words: G protein-coupled receptor 4, Notch1, angiogenesis responses (3). RBP-J $\kappa$ activates the expression of target genes in cells receiving the Notch signal and represses target expression in the non-receiving cells. This dual role of RBP-J $\kappa_{\kappa}$ allows a fine spatial and temporal control of Notch-regulated transcription; however, the underlying mechanism is not fully understood (1).

The $G$ protein-coupled receptor 4 (GPR4) family of proton-sensing $G$ protein-coupled receptors (GPCRs) has recently been identified to be novel $\mathrm{pH}$ sensors (4-6). GPR4, originally cloned as an orphan GPCR, is expressed in a wide range of tissues, such as the lung, kidney, heart and liver (7). GPR4 is highly conserved during evolution, with $>90 \%$ amino acid sequence homology among mammalian orthologs and $>70 \%$ homology between human and zebrafish orthologs. GPR4 was previously reported as a receptor for sphingosylphosphorylcholine and lysophosphatidylcholine, however, this observation has not been consistently confirmed and the original publication was withdrawn $(8,9)$. Our previous in vitro study indicated that GPR4 is capable of mediating the tube formation of blood vessels by regulating the function of endothelial cells (ECs) $(10,11)$. When GPR4 was knocked down in ECs, the growth, migration and tube formation of ECs were significantly inhibited. In addition, the GPR4 expression levels appear to be associated with EC survival. When GPR4 was restored in ECs with GPR4 knocked down, the growth, migration, and tube formation of ECs fully recovered, confirming the critical role of this protein for healthy EC function. In vivo studies have provided further evidence in support of the GPR4 functions in angiogenesis $(4,12)$. Dilated and tortuous subcutaneous blood vessels, spontaneous hemorrhages, and defective vascular smooth muscle cell coverage were found in $\sim 17 \%$ of GPR4-null embryos and neonates (4). These observations indicated that GPR4 is required for the normal vascular development of multiple tissues/organs. However, the mechanism by which GPR4 regulates the angiogenesis of ECs has not been clearly defined to the best of our knowledge.

In the current study, the human (h)GPR4 protein was associated with the Notch1 protein in ECs and was observed to be essential in tube formation in the Notch signaling pathway in vitro. 


\section{Materials and methods}

Cell culture and reagents. Human HMEC-1 cells were purchased from the Centers for Disease Control and Prevention (Atlanta, GA, USA). The HMEC-1 cells were cultured at $37^{\circ} \mathrm{C}$ in $5 \% \mathrm{CO}_{2}$ in Gibco Dulbecco's modified Eagle's medium (DMEM) supplemented with Gibco $10 \%$ (v/v) fetal bovine serum (FBS), $100 \mu \mathrm{g} \mathrm{ml}^{-1}$ penicillin and $10 \mu \mathrm{g} \mathrm{ml}^{-1}$ streptomycin (all purchased from Thermo Fisher Scientific, Inc., Waltham, MA, USA). Cells were passaged every 2-3 days. Suspensions of HMEC-1 cells were produced from confluent cultures using trypsin/EDTA solution and the cell concentration determined using a Burker hemocytometer (Neubauer, Darmstadt, Germany). HMEC-1 cells were seeded at $1 \times 10^{6}$ either directly into wells of a standard 6-well plate or into modified well-inserts, which were mounted with the polymer and located in the wells of a 6-well plate. The growth medium was replaced every day or as required. The Notch receptor inhibitor, $\gamma$-secretase inhibitor I (GSI-I; Z-LLNle-CHO) was obtained from EMD Millipore (Billerica, MA, USA).

GSI-I $(100 \mu \mathrm{M})$ was dissolved in distilled water and stored at $-20^{\circ} \mathrm{C}$ as a stock solution. Prior to treatment with GSI-I, the cells were starved with low-serum medium (containing $0.5 \%$ FBS) for $24 \mathrm{~h}$. To block the Notch signaling pathway, $1 \mu \mathrm{M}$ GSI-I was added to the medium for $24 \mathrm{~h}$.

Luciferase reporter assay. The HMEC-1 cells were transfected with the pcDNA3-hGPR4 plasmid for $24 \mathrm{~h}$ and infected with the Lenti-RBP-JK Reporter lentiviruses [a section of the RBP-Jא target sequence, CGTGGGAA (repeated four times), with the luciferase gene], which was obtained from Qiagen China Co., Ltd., (Shanghai, China). Following a 48-h transfection, the cells were lysed in chemiluminescence lysis buffer $\left[18.3 \% 1 \mathrm{~m} \mathrm{~K}_{2} \mathrm{HPO}_{4}, 1.7 \% 1 \mathrm{~m} \mathrm{K \textrm {K } _ { 2 }} \mathrm{PO}_{4}, 1 \mathrm{mM}\right.$ phenylmethylsulfonyl fluoride (PMSF), and $1 \mathrm{mM}$ dithiothreitol] and luciferase activity was assayed using a luciferase assay kit (cat. no. E1910; Promega Corporation, Madison, WI, USA). The results were presented as the mean \pm standard deviation (SD) of three independent experiments.

Reverse transcription-quantitative polymerase chain reaction $(R T-q P C R)$. Total RNA was extracted from the HMEC-1 cells using Invitrogen TRIzol reagent (Thermo Fisher Scientific, Inc.) and RNA aliquots $(200 \mathrm{ng})$ were reverse transcribed using Random Rochez (Roche Diagnostics GmbH, Mannheim, Germany) and Reverse Transcriptase (Takara Biotechnology Co., Ltd., Dalian, China), according to the manufacturer's protocol. qPCR was performed with the LightCycler ${ }^{\circledR} 480$ (Roche Diagnostics) and the Real-Time detection system (Roche Diagnostics) was used according to the following conditions: $95^{\circ} \mathrm{C}, 1 \mathrm{~min}$; and $40 \mathrm{cycles}$ of $98^{\circ} \mathrm{C}$ for $5 \mathrm{sec}$ and $60^{\circ} \mathrm{C}$ for $20 \mathrm{sec}$. qPCR of the core genes, Notch, GAPDH, $\beta$-2-microglobulin $(B 2 M)$, actin, $\beta$ (ACTB), hypoxanthine phosphoribosyltransferase (HPRTI) and ribosomal protein, large, PO (RPLPO) was performed using the $\mathrm{RT}^{2}$ Profiler $^{\mathrm{TM}}$ PCR Array (Qiagen China Co., Ltd.,) for the human Notch signaling pathway. Reactions were conducted, and gene expression levels were calculated relative to $G A P D H, B 2 M, A C T B, H P R T 1$ and $R P L P O$ mRNA levels, which served as endogenous controls. Relative expression was calculated as $2^{\text {(Cq gene under investigation - } \mathrm{Cq} \mathrm{GAPDH})}$.
Tube formation assay. Growth factor-reduced Matrigel (BD Biosciences, San Jose, CA, USA) was dissolved at $4^{\circ} \mathrm{C}$ overnight, and $50 \mu \mathrm{l}$ was pipetted onto the 96 -well culture plates and allowed to polymerize for $2 \mathrm{~h}$ at $37^{\circ} \mathrm{C}$. Three quaters of the HMEC-1 cells were transfected with pcDNA3-hGPR4. After $24 \mathrm{~h}, 3 \times 10^{4}$ cells were plated on 96-well plates coated with the Matrigel and incubated for $8 \mathrm{~h}$ with or without $1 \mu \mathrm{M}$ GSI-I. Images of the cells were obtained using an Olympus BX-60 digital camera (Olympus Corporation, Tokyo, Japan). Three randomly selected fields of view were photographed per well, and the average was calculated, using ImageJ software, version 1.47 (National Institutes of Health, Bethesda, MD, USA), to analyze the length of the total capillary structure.

Gene silencing using small interfering (si)RNA. siRNAs against Notch1 (siNotch1) or the non-specific RNAi (siCon) were purchased from Dharmacon, Inc., (Lafayette, CO, USA). The Notch1 sequence: 5'-AAGTGTCTGAGGCCAGCA AGA-3' was as reported by Rizzo et al (13). Cells $\left(2 \times 10^{5}\right)$ were plated in a 6-well plate and cultured for $24 \mathrm{~h}$ prior to transfection to reach $\sim 50 \%$ confluence. The cells were transfected with $50 \mathrm{nM}$ siRNA against Notch1 in the presence of $2.5 \mu 1$ Invitrogen Lipofectamine ${ }^{\circledR} 2000$ (Thermo Fisher Scientific, Inc.), in a final volume of $1 \mathrm{ml}$ serum-free DMEM/HIGH glucose medium. The reaction was stopped following $6 \mathrm{~h}$ of treatment and the medium was replaced with fresh $10 \%$ FBS supplemented medium.

Preparation of cell extracts and western blotting analysis. The cells were lysed in lysis buffer [50 mM Tris (pH 7.5), $100 \mathrm{mM} \mathrm{NaCl}, 1 \mathrm{mM}$ EDTA, $0.5 \% \mathrm{NP}-40,0.5 \%$ Triton $\mathrm{X}-100,2.5 \mathrm{mM}$ sodium orthovanadate, $10 \mathrm{mM}$ protease inhibitor cocktail and $1 \mathrm{mM}$ PMSF) by incubating for $20 \mathrm{~min}$ at $4^{\circ} \mathrm{C}$. The protein concentration was determined using the Bio-Rad assay system (Bio-Rad Laboratories, Inc., Hercules, CA, USA). Total proteins $(20 \mu \mathrm{g})$ were fractionated using 12\% SDS-PAGE (Sigma-Aldrich, St. Louis, MO, USA) and transferred onto a polyvinylidene fluoride membrane (EMD Millipore). The membranes were blocked with 5\% nonfat dried milk in $1 \mathrm{X}$ Tris-buffered saline buffer containing $0.1 \%$ Tween-20 and subsequently incubated with the following primary antibodies: Polyclonal rabbit anti-Notch1 (1:1,000; cat. no. ab27526; Abcam, Cambridge, MA, USA), monoclonal mouse anti-HIF1 $\alpha$ (1:1,000; cat. no. ab113642; Abcam), polyclonal rabbit anti-VEGF (1:500; cat. no. ab46154; Abcam) and monoclonal mouse anti-GAPDH (1:1,000; cat. no. ab8245; Abcam). Horseradish peroxidase (HRP)-conjugated goat anti-rabbit IgG (1:10,000 dilution; ab6721; Abcam) or HRP-conjugated goat anti-mouse IgG (1:10,000 dilution; ab97023; Abcam) was used as the secondary antibodies, and the protein bands were detected using an enhanced chemiluminescence detection system (Santa Cruz Biotechnology, Inc., Dallas, TX, USA). The western blot products were imaged using the Fusion FX6 system (Vilber Lourmat Deutschland GmbH, Eberhardzell, Germany). Quantification of the western blots was performed using laser densitometry, and the relative protein expression was normalized to the GAPDH levels in each sample. The results are presented as the mean of three independent experiments with error bars representing SDs. 
A

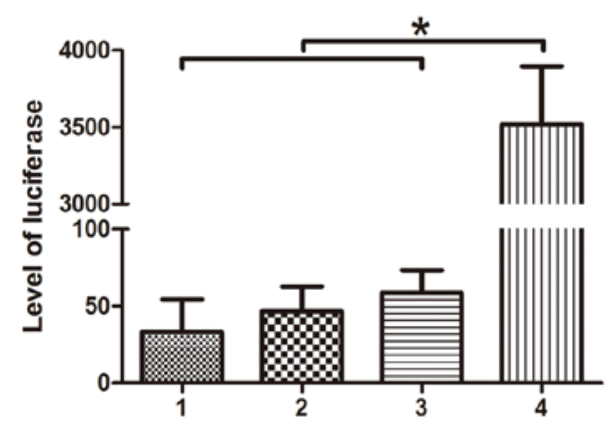

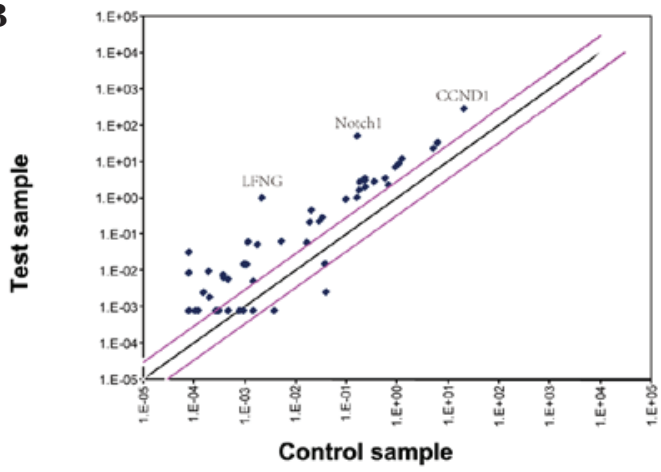

Figure 1. Transcriptional regulation of Notch target genes following pcDNA3-hGPR4 transfection in HMEC-1 cells. (A) HMEC-1 cells were transfected with pcDNA3-hGPR4 for $24 \mathrm{~h}$. Then the cells were infected with the lentivirus-mediated RBP-JK reporter for $24 \mathrm{~h}$. The luciferase activity was detected using a luciferase assay kit. 1, HMEC-1 blank cells; 2, HMEC-1 cells transfected with pcDNA3-hGPR4; 3, HMEC-1 cells infected with lentivirus without RBP-Jא reporter; 4, HMEC-1 cells infected with lentivirus-mediated RBP-Jк reporter. "P<0.0001. (B) Transcriptional regulation of Notch target genes following pcDNA3-hGPR4 treatment in HMEC-1 cells. cDNA was synthesized from HMEC-1 cells before and after treatment with pcDNA3-hGPR4. A mini-array of Notch-relevant genes demonstrates that few genes were downregulated upon pcDNA3-hGPR4 treatment; however, certain significant genes including LFNG, Notch1 and CCND1 were upregulated. The gray lines indicate a two-fold change. hGPR4, human G protein-coupled receptor 4; RBP-Jк, recombination signal sequence binding protein-J $\kappa$; LFNG, LFNG O-fucosylpeptide 3- $\beta$-N-acetylglucosaminyltransferase; CCND1, cyclin D1.

A

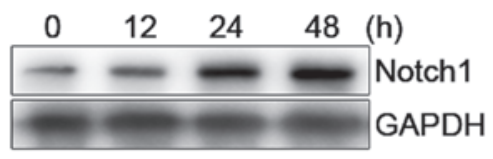

B

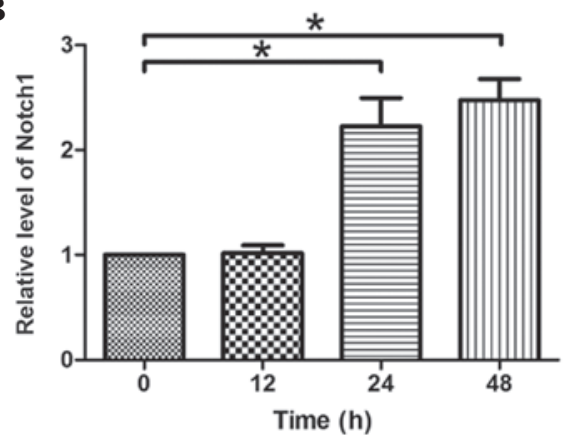

Figure 2. hGPR4 induces the expression of Notch1 in HMEC-1. (A) HMEC-1 were treated with pcDNA3-hGPR4 for 0, 12, 24 and 48 h. Cell lysates were electrophoresed and immunoblotted with Notch1 antibody. GAPDH antibody was used to ensure equal loading. (B) Densitometric analysis of the western blot assay to quantify the target protein levels. Results are expressed as mean \pm standard deviation of three independent experiments. ${ }^{*} \mathrm{P}<0.05$. hGPR4, human G protein-coupled receptor 4 .

Transendothelial migration. Migration assays were performed in Transwell plates (Corning Incorporated, Corning, NY, USA) with a $6.5-\mathrm{mm}$ diameter and $3-\mu \mathrm{m}$ pore filters. The ECs were plated at $3 \times 10^{4}$ cells/well on gel-coated filters. The nonadherent cells were removed after $18 \mathrm{~h}$. The adherent cells were cultured for 2-3 days to obtain $100 \%$ confluence. Freshly isolated lymphocytes $\left(1 \times 10^{5}\right)$ were added to the upper compartment in $0.1 \mathrm{ml}$ serum-free medium with or without hGPR4/GSI-I, and $0.6 \mathrm{ml}$ serum-free medium was added to the lower compartment. The Transwell plates were incubated at $37^{\circ} \mathrm{C}$ and at $5 \%$ $\mathrm{CO}_{2}$ for $6 \mathrm{~h}$. The cells that did not migrate were removed using a cotton swab, whereas the cells that migrated were fixed with $4 \%$ paraformaldehyde and stained with $1 \%$ crystal violet. The cells that migrated to the lower compartment were collected and counted. The membrane was then fixed in formalin for $10 \mathrm{~min}$ at room temperature prior to staining with $0.1 \%$ crystal violet for $5 \mathrm{~min}$. The number of HMEC-1 cells that migrated to the lower surface of the membrane were counted in 10 random fields at maginification, x100 using a light microscope (Leica Microsystems GmbH, Wetzlar, Germany). A chemotactic index (CI) was calculated to express stimulated migration: $\mathrm{CI}=$ treated migration (number of HMEC-1 per field)/random migration (number of HMEC-1 per field). Each assay was performed in triplicate wells.

Statistical analysis. Data were analyzed using the two-tailed Student's t-test using SPSS software, version 19.0 (IBM SPSS, Armonk, NY, USA). $\mathrm{P}<0.05$ was considered to indicate a statistically significant difference.

\section{Results}

hGPR4 induces the expression of Notchl in HMEC-1. As Notch signaling has a profound effect on angiogenesis, the involvement of Notch signaling in hGPR4-induced angiogenesis was examined. HMEC-1 cells were transfected with pcDNA3-hGPR4 for $24 \mathrm{~h}$. Then the cells were infected with the lentivirus-mediated RBP-JK reporter for $24 \mathrm{~h}$. As shown in Fig. 1A, following treatment with hGPR4 for $48 \mathrm{~h}$, the level of luciferase was upregulated significantly. Using validated Notch cDNA microarray datasets, the mRNA expression of Notch-related genes in HMEC-1 with or without pcDNA3-hGPR4 transfection were compared. Notch1 was identified to be the predominant Notch receptor expressed, 
A

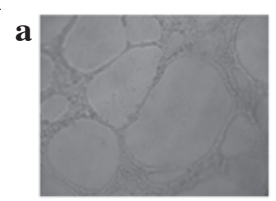

C

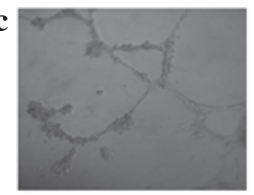

C

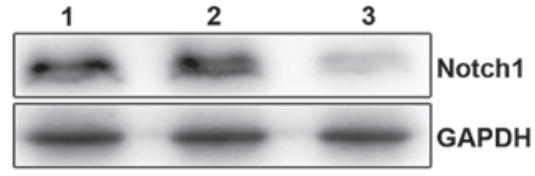

E
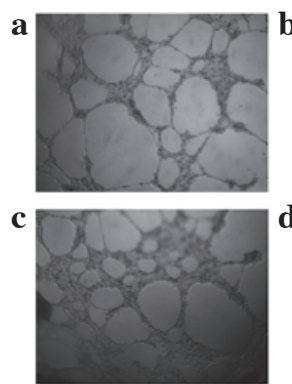
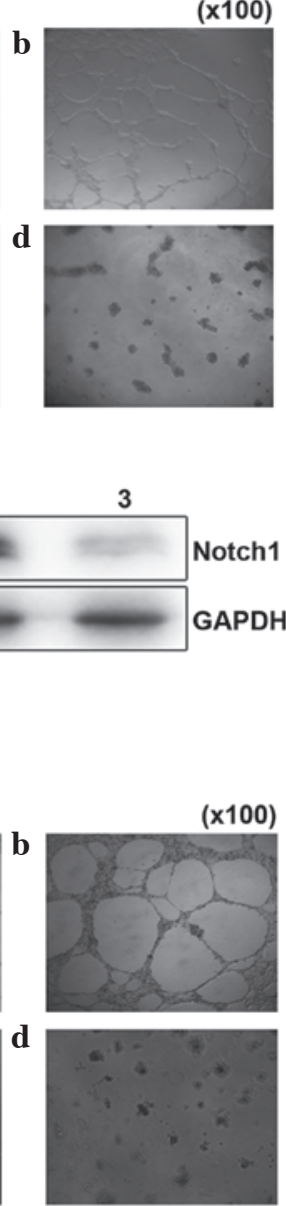

B

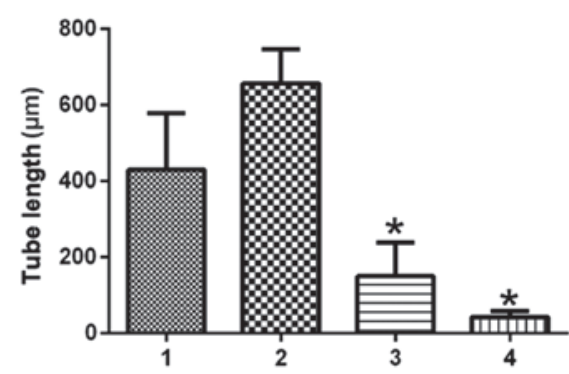

D

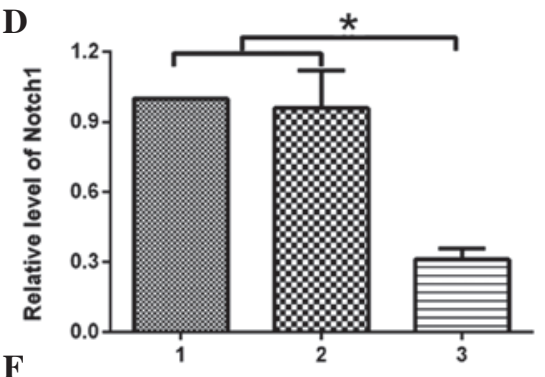

$\mathbf{F}$

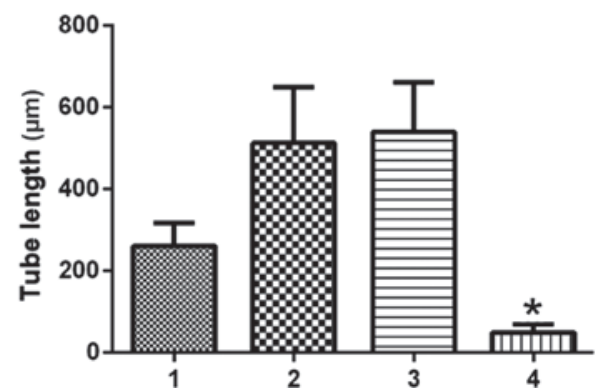

Figure 3. Notch1 participates in HMEC-1 tube formation induced by hGPR4. (A) HMEC-1 cells treated with pcDNA3-hGPR4, $1 \mu$ M GSI-I and a combination of the two (magnification, x100). (a) Blank HMEC-1 cells served as a control; (b) HMEC-1 cells transfected with pcDNA3-hGPR4; (c) HMEC-1 cells treated with pcDNA3-hGPR4 and siNotch1; (d) HMEC-1 cells transfected with pcDNA3-hGPR4 and treated with GSI-I. (B) The tube length was quantified in eight fields after the corresponding treatment. 1, Blank HMEC-1 cells served as a control; 2, HMEC-1 cells transfected with pcDNA3-hGPR4; 3, HMEC-1 cells treated with pcDNA3-hGPR4 and siNotch1; 4, HMEC-1 cells transfected with pcDNA3-hGPR4 and then treated with GSI-I. (C) HMEC-1 cells transfected with pcDNA3-hGPR4 and then treated with GSI-I. The cell lysates were also subjected to western blot analysis with anti-Notch1 antibody. The antibody to GAPDH served as a loading control. 1, HMEC-1 cells; 2, HMEC-1 cells transfected by pcDNA3-hGPR4; 3, HMEC-1 cells transfected with pcDNA3-hGPR4 and GSI-I. (D) Densitometric analysis of western blot assay to quantify target protein levels. Results are expressed as mean \pm standard deviation of three independent experiments, ${ }^{*} \mathrm{P}<0.05$ vs. the control. (E) HMEC-1 cells treated with pcDNA3-hGPR4, siCon or siNotch1 (magnification, x100); (a) Blank HMEC-1 cells served as a control; (b) HMEC-1 cells transfected with pcDNA3-hGPR4 and siCon; (c) HMEC-1 cells transfected with pcDNA3-hGPR4; (d) HMEC-1 cells transfected with siNotch1. (d) HMEC-1 cells transfected with pcDNA3-hGPR4 and siNotch1. (F) The tube length was quantified in eight fields after the corresponding treatment. 1, Blank HMEC-1 cells served as a control; 2, HMEC-1 cells transfected with pcDNA3-hGPR4 and siCon; 3, HMEC-1 cells transfected with pcDNA3-hGPR4; 4, HMEC-1 cells transfected with pcDNA3-hGPR4 and siNotch1. "P<0.05. hGPR4, human G protein-coupled receptor 4; GSI-I, $\gamma$-secretase inhibitor I; si, small interfering; siCon, non-specific RNAi.

although Notch2, 3 and 4 were detected at low levels in the HMEC-1 cells. A higher level of expression of Notch1, CCND1 and LFNG were observed in HMEC-1 with pcDNA3-hGPR4 transfection (Fig. 1B).

HMEC-1 cells were transfected with pcDNA3-hGPR4 for 12, 24 and 48 h. As shown in Fig. 2A and B, after treatment with pcDNA3-hGPR4 for $12 \mathrm{~h}$, the expression of Notch1 was demonstrated to be markedly enhanced and reached its maximum at $48 \mathrm{~h}$. Notch1 demonstrated a time-dependent response to hGPR4.

Notch1 participates in hGPR4-induced HMEC-1 tube formation. In a previous study, the function of hGPR4 in angiogenesis was demonstrated in the tube formation test $(14,15)$, and the present study showed similar results; as hGPR4 significantly enhanced HMEC-1 tube formation when compared with a

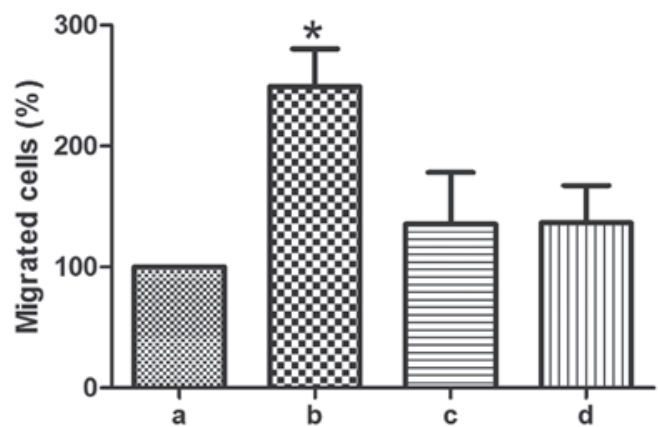

Figure 4. hGPR4 induces lymphocyte transendothelial migration through Notch1. HMEC-1 was transfected with pcDNA3-hGPR4 and then treated with siNotch1 or GSI-I $(1 \mu \mathrm{M})$ under different experimental conditions: a, Control cells; b, HMEC-1 treated with pcDNA3-hGPR4; c, HMEC-1 treated with pcDNA3-hGPR4 and transfected with siNotch1; d, HMEC-1 transfected with pcDNA3-hGPR4 and treated with GSI-I. * $\mathrm{P}<0.05$. hGPR4, human G protein-coupled receptor 4; GSI-I, $\gamma$-secretase inhibitor I; si, small interfering. 
A

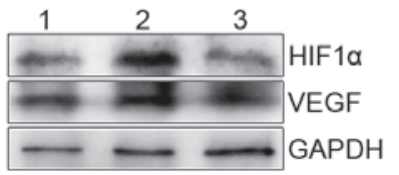

B

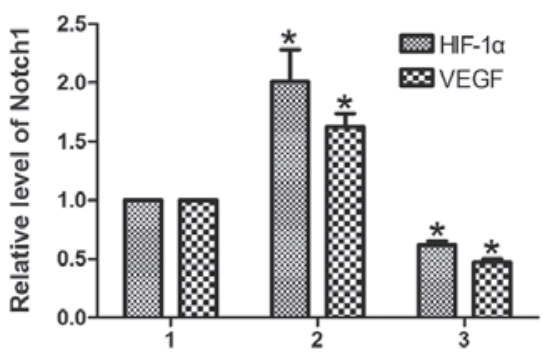

Figure 5. Notch1 mediated hGPR4 regulation of VEGF and HIF-1 $\alpha$. 1, control cells; 2, HMEC-1 treated with pcDNA3-hGPR4; 3, HMEC-1 treated with pcDNA3-hGPR4 and transfected with siNotch1. (A) HMEC-1 transfected with pcDNA3-hGPR4 and treated with siNotch1 for 48 h under different experimental conditions. Cell lysates were electrophoresed and immunoblotted with HIF-1 $\alpha$ and VEGF antibody to detect changes in the target protein expression. GAPDH antibody was used to ensure equal loading. (B) Densitometric analysis of western blot assay to quantify target protein levels. Results are expressed as mean \pm standard deviation of three independent experiments, ${ }^{*} \mathrm{P}<0.05$ vs. the control. hGPR4, human G protein-coupled receptor 4 ; VEGF, vascular endothelial growth factor; HIF-1 $\alpha$, hypoxia-inducible factor $1 \alpha$; si, small interfering.

control group without hGPR4. To further estimate whether Notch signaling is involved in hGPR4-induced tube formation, the Notch inhibitor, GSI-I was used. GSI-I $(1 \mu \mathrm{M})$ markedly inhibited hGPR4-induced tube formation. Tube lengths were significantly decreased from $430.67 \pm 148.41$ in the control cells to $150.0 \pm 89.27 \mu \mathrm{m}$ in the HMEC-1 cells treated with pcDNA3-hGPR4 and siNotch1 ( $\mathrm{P}=0.0485$; Fig. 3A and B).

As it has previously been demonstrated that GSIs are able to act through different biochemical pathways (16), the present study investigated whether the effects induced by GSI-I were associated with the specific inhibition of Notch signaling, which is induced by GSI-I. The Notch gene was silenced and the effects of hGPR4 addition were evaluated. An siRNA sequence was obtained for the knockdown of Notch1. After confirming the reduction in Notch1 expression level (Fig. 3C and D), the effect of hGPR4 on HMEC-1 tube formation activity was analyzed. As shown in Fig. 3E and F, Notch1 siRNA significantly inhibited hGPR4-induced tube formation from $540.0 \pm 121.45$ to $49.67 \pm 19.50 \mu \mathrm{m}(\mathrm{P}=0.0143)$, while siCon did not exert an effect hGPR4-induced tube formation.

HGPR4 induces lymphocyte transendothelial migration through Notchl. Vascular leakage and lymphocyte transendothelial migration are the critical, initial steps in angiogenesis. To detect if Notch signaling is involved in hGPR4-induced lymphocyte transendothelial migration, GSI-I and siNotch were used. As shown in Fig. 4, $1 \mu \mathrm{M}$ GSI-I significantly decreased hGPR4-induced lymphocyte transendothelial migration. hGPR4-induced lymphocyte transendothelial migration was also significantly attenuated from $249.02 \pm 31.45$ to 135.29 \pm 42.72 with Notch1 knockdown $(\mathrm{P}=0.0116)$.

Notchl mediates hGPR4 regulation of VEGF and HIF-1 $\alpha$. VEGF is considered to be the most important gene in angiogenesis. The present study aimed to determine whether hGPR4 also regulates VEGF via Notch signaling. It was found that hGPR4 overexpression significantly induced VEGF expression (Fig. 5A). VEGF expression was significantly attenuated by the knockdown of Notch1, when compared with cells transfected with control cells (Fig. 5A).

Subsequently, whether HGPR4 regulates HIF-1 $\alpha$ and whether this regulation is also through Notch signaling was investigated, as HIF-1 $\alpha$ is the main mediator of VEGF and controls the upregulation of VEGF. As demonstrated in Fig. 5, hGPR4 significantly augmented HIF-1 $\alpha$ expression when compared with the control, while siNotch1 significantly inhibited hGPR4-induced HIF-1 $\alpha$ expression.

\section{Discussion}

The results of the present study demonstrated the Notch involvement in EC activation, apoptosis and proliferation. Although the effects of various mediators of cell fate on the Notch signaling pathway in ECs have been characterized, little is known about the role of hGPR4 upon Notch in ECs $(13,17)$.

The requirement for Notch signaling in vasculogenesis and angiogenesis is well documented in a number of studies. Hellstrom et al (18) report that delta-like 4 (DLL4)-Notch1 signalling regulates the formation of appropriate numbers of tip cells to control vessel sprouting and branching in the mouse retina. Yang et al (19) reported that differential activation of the hypoxia/HIF1-VEGF-Notch pathway may serve a role in epicardial cell interactions that promote epicardial epithelial/mesenchymal transition and coronary progenitor cell differentiation during epicardial development and coronary vasculogenesis, particularly in hypoxic sulcus regions. Notch1, the key regulator of vasculogenesis and embryonic differentiation, has shown a correlation with a poor prognosis in hepatocellular carcinoma (HCC). Notch1 may serve as a potential target for vasculogenic mimicry development in HCC (20). Notch signaling is reported to regulate angiogenesis by interacting with VEGF signaling. Increasing evidence indicates that Notch signaling promotes angio/arteriogenesis not only in developmental states but also in ischemia-induced angiogenesis in adults $(21,22)$. Additionally, Notch signal activation regulates VEGF receptor expression and angiogenic activity in endothelial cells in a ligand-dependent manner. DLL4-mediated Notch signaling suppresses tip cells sprouting in the retina, which is antagonized by Notch signal activation by Jagged-1 (23). Thus, negative and positive roles for Notch signaling in endothelial sprouting and angiogenetic activity have been reported in a number of previous studies. In the present study, the relationship between hGPR4 and Notch1 was investigated. These findings suggest that Notch1 is an important downstream target of hGPR4 in vascular endothelial cells. Although it remains largely unknown why in some 
endothelial cells had to develop into mature endothelium while vasculogenic mimicry may already serve the same purpose, it has been demonstrated that Notch1 might contribute to these processes.

In the current study, the results showed that the

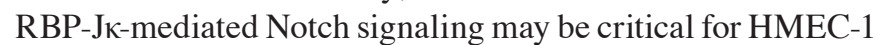
tube formation. The Notch signaling pathway is important in cell-cell communication, and the self-renewal, migration and differentiation of cells $(1,24)$. The present study identified a positive role for Notch signaling in endothelial morphogenesis via the induction of cellular extensions mediated by Notch1. This finding was supported by the observation that the Notch signaling pathway is involved in the regulation of VEGF and HIF- $1 \alpha$ levels, and the increase of VEGF and HIF-1 $\alpha$ levels correlated with increased endothelial responsiveness to the Notch1. It was found that Notch signaling increased angiogenesis by inducing Notch1 expression.

The present study demonstrated that Notch1 is upregulated by Notch signaling in ECs following hGPR4 overexpression. A positive role for Notch signaling was identified in endothelial morphogenesis via the induction of cellular extensions, which were mediated by hGPR4. This was demonstrated by the observation that overexpression of hGPR4 increased Notch1 expression levels and this increase correlated with increased endothelial form of HMEC-1 in vitro. Using a protein-based Notch inhibitor, GSI-I, the current study demonstrated that the perturbation of endogenous Notch signaling resulted in reduced VEGF and HIF-1 $\alpha$ expression levels. Thus, loss- and gain-of-function studies reveal that hGPR4 regulates Notch signaling expression in HMEC-1 cells.

\section{Acknowledgements}

The present study was supported by the National Natural Science Foundations of China (grant nos. 31201060/C0709, 30973175/H1621 and 81172490/H1621); the Program for New Century Excellent Talents in University (grant no. NCET-12-0440); the Scientific and Technological Research Foundation of Shaanxi Province (grant nos. 2012K13-01-06 and 2007K09-09); the project was sponsored by the Scientific Research Foundation for the Returned overseas Chinese Scholars of State Education Ministry, (grant no. 0601-18920006); the Research Foundation of the Health Department of Shaan'xi Province (grant no. 2010D41); Qing Nian Jiao Shi Gen Zong Ji Hua of Xi'an Jiaotong University ("The Fundamental Research Funds for the Central Universities'; grant no. 2012-FRFCU-121); and supported by the Program for Changjiang Scholars and Innovative Research Team in University (grant no. PCSIRT:1171) and the Research Foundation of Xi'an Jiao Tong University of China (grant no. RFXJTU:1231).

\section{References}

1. Kopan R and Ilagan MX: The canonical Notch signaling pathway: Unfolding the activation mechanism. Cell 137: 216-233, 2009.

2. Bray SJ: Notch signalling: A simple pathway becomes complex. Nat Rev Mol Cell Biol 7: 678-689, 2006.

3. Borggrefe $\mathrm{T}$ and Oswald F: The Notch signaling pathway: transcriptional regulation at Notch target genes. Cell Mol Life Sci 66: 1631-1646, 2009.
4. Yang LV, Radu CG, Roy M, Lee S, McLaughlin J, Teitell MA, Iruela-Arispe ML and Witte ON: Vascular abnormalities in mice deficient for the $\mathrm{G}$ protein-coupled receptor GPR4 that functions as a pH sensor. Mol Cell Biol 27: 1334-1347, 2007.

5. Ludwig MG, Vanek M, Guerini D, Gasser JA, Jones CE, Junker U, Hofstetter H, Wolf RM and Seuwen K: Proton-sensing G-protein-coupled receptors. Nature 425: 93-98, 2003.

6. Murakami N, Yokomizo T, Okuno T and Shimizu T: G2A is a proton-sensing G-protein-coupled receptor antagonized by lysophosphatidylcholine. J Biol Chem 279: 42484-42491, 2004.

7. Mahadevan MS, Baird S, Bailly JE, Shutler GG, Sabourin LA, Tsilfidis C, Neville CE, Narang M and Korneluk RG: Isolation of a novel G protein-coupled receptor (GPR4) localized to chromosome 19q13.3. Genomics 30: 84-88, 1995.

8. Bektas M, Barak LS, Jolly PS, Liu H, Lynch KR, Lacana E, Suhr KB, Milstien S and Spiegel S: The G protein-coupled receptor GPR4 suppresses ERK activation in a ligand-independent manner. Biochemistry 42: 12181-12191, 2003.

9. Zhu K, Baudhuin LM, Hong G, Williams FS, Cristina KL, KabarowskiJH,Witte ON and Xu Y:Sphingosylphosphorylcholine and lysophosphatidylcholine are ligands for the $\mathrm{G}$ protein-coupled receptor GPR4. J Biol Chem 276: 41325-41335, 2001.

10. Kim KS, Ren J, Jiang Y, Ebrahem Q, Tipps R, Cristina K, Xiao YJ, Qiao J, Taylor KL, Lum H, et al: GPR4 plays a critical role in endothelial cell function and mediates the effects of sphingosylphosphorylcholine. FASEB J 19: 819-821, 2005.

11. Afrasiabi E, Blom T, Ekokoski E, Tuominen RK and Törnquist K: Sphingosylphosphorylcholine enhances calcium entry in thyroid FRO cells by a mechanism dependent on protein kinase C. Cell Signal 18: 1671-1678, 2006.

12. Wyder L, Suply T, Ricoux B, Billy E, Schnell C, Baumgarten BU, Maira SM, Koelbing C, Ferretti M, Kinzel B, et al: Reduced pathological angiogenesis and tumor growth in mice lacking GPR4, a proton sensing receptor. Angiogenesis 14: 533-544, 2011.

13. Rizzo P, Miao H, D'Souza G, Osipo C, Song LL, Yun J, Zhao H, Mascarenhas J, Wyatt D, Antico G, et al: Cross-talk between notch and the estrogen receptor in breast cancer suggests novel therapeutic approaches. Cancer Res 68: 5226-5235, 2008.

14. Kim KS, Ren J, Jiang Y, Ebrahem Q, Tipps R, Cristina K, Xiao YJ, Qiao J, Taylor KL, Lum H, et al: GPR4 plays a critical role in endothelial cell function and mediates the effects of sphingosylphosphorylcholine. FASEB J 19:819-821, 2005.

15. Ren J, Jin W, Gao YE, Zhang Y, Zhang X, Zhao D, Ma H, Li Z, Wang J, Xiao L, et al: Relations between GPR4 expression, microvascular density (MVD) and clinical pathological characteristics of patients with epithelial ovarian carcinoma (EOC). Curr Pharm Des 20: 1904-1916, 2014.

16. Rasul S, Balasubramanian R, Filipović A, Slade MJ, Yagüe $\mathrm{E}$ and Coombes RC. Inhibition of gamma-secretase induces $\mathrm{G} 2 / \mathrm{M}$ arrest and triggers apoptosis in breast cancer cells. $\mathrm{Br}$ J Cancer 100: 1879-1888, 2009.

17. Funahashi Y, Shawber CJ, Vorontchikhina M, Sharma A, Outtz HH and Kitajewski J: Notch regulates the angiogenic response via induction of VEGFR-1. J Angiogenes Res 2: 3, 2010.

18. Hellstrom M, Phng LK, Hofmann JJ, Wallgard E, Coultas L, Lindblom P, Alva J, Nilsson AK, Karlsson L, Gaiano N, et al: Dl14 signalling through Notch1 regulates formation of tip cells during angiogenesis. Nature 445: 776-780, 2007.

19. Yang K, Doughman YQ, Karunamuni G, Gu S, Yang YC, Bader DM and Watanabe M: Expression of active Notch1 in avian coronary development. Dev Dyn 238: 162-170, 2009.

20. Zhu MS, Xu LB, Zeng H, Shi XD, Wu WR and Liu C: Association of Notch1 with vasculogenic mimicry in human hepatocellular carcinoma cell lines. Int J Clin Exp Pathol 7: 5782-5791, 2014.

21. Takeshita K, Satoh M, Ii M, Silver M, Limbourg FP, Mukai Y, Rikitake Y, Radtke F, Gridley T, Losordo DW and Liao JK: Critical role of endothelial Notch1 signaling in postnatal angiogenesis. Circ Res 100: 70-78, 2007.

22. Funahashi Y, Shawber CJ, Vorontchikhina M, Sharma A, Outtz $\mathrm{HH}$ and Kitajewski J: Notch regulates the angiogenic response via induction of VEGFR-1. J Angiogenes Res 2: 3, 2010.

23. Suchting S, Freitas C, le Noble F, Benedito R, Bréant C, Duarte A, Eichmann A: The Notch ligand Delta-like 4 negatively regulates endothelial tip cell formation and vessel branching. Proc Natl Acad Sci U S A 104: 3225-3230, 2007.

24. Yang B, Tang Q, Post J, Zhou H, Huang XB, Zhang XD, Wang Q, Sun YM and Fan FY: Effect of radiation on the Notch signaling pathway in osteoblasts. Int J Mol Med 31: 698-706, 2013. 